\title{
Alzheimer's: Phytotherapy and the most important herbs in the treatment of Alzheimer's
}

\author{
Elaheh Karimi ${ }^{1}$ \\ ${ }^{1}$ Biotechnology and Medicinal Plants Research Center, Ilam University of Medical Sciences, Ilam, Iran
}

\section{*Correspondence to: \\ Dr. Elaheh Karimi \\ elahehkarimi3913@gmail.com}

Received: 04 March 2020

Accepted: 02 April 2020

ePublished: 16 June 2020

Keywords: Alzheimer, Medicinal plants, Drug.

\section{Citation:}

Karimi E. Alzheimer's: Phytotherapy and the most important herbs in the treatment of Alzheimer's. Plant Biotechnology Persa. 2020; 2(1): 61-62.

\section{Abstract}

Alzheimer's disease is a progressive form of dementia that causes problems with memory, thinking, and behavior. This disease is associated with profound effects on intelligence, self-care, speech impairment, and dysfunction, motor functional and cognitive impairment. This letter discusses some of the most important herbal plants used for Alzheimer's disease. Herbs such as Petroselinum crispum, Thymus vulgaris, Hypericum perforatum, Matricaria chamomilla, Salvia officinalis, Allium sativum, Ziziphus jujube, Lavandula officinalis, Curcuma longa, Salvia Rosmarinus and Cyperus rotundus are considered to treat Alzheimer's. Medicinal herbs can be used in the treatment of Alzheimer's and they can be produced in the future as effective natural anti-Alzheimer's drugs.

\section{Dear editor:}

Alzheimer's disease is a progressive form of dementia that causes problems with memory, thinking, and behavior. This disease is associated with profound effects on intelligence, self-care, speech impairment, and dysfunction, motor functional and cognitive impairment [1]. Memory loss is usually the first symptom that occurs in Alzheimer's disease. However, remote memory performs better than Shortterm memories [2]. It is estimated that there are approximately 44 million people worldwide have Alzheimer's disease or a related form of dementia. This number is estimated to increase to 130 million by 2050 [3]. Alzheimer's disease is both preventable and partially controlled by both modern and traditional medicine. Some drugs affect one neurotransmitter or class of neurotransmitters like selegiline and rivastigmine, as well as antioxidants such as vitamin $\mathrm{E}$. Traditional medicine and herbs, have also been shown to reduce the symptoms of Alzheimer's disease. This letter discusses some of the most important medicinal plants used for Alzheimer's. Medicinal plants such as Petroselinum crispum, Thymus vulgaris, Hypericum perforatum, Matricaria chamomilla, Salvia officinalis, Allium sativum, Ziziphus jujube, Lavandula officinalis, Curcuma longa, Salvia Rosmarinus and Cyperus rotundus are considered to treat Alzheimer's.

Petroselinum crispum contains useful essential volatile oils, including myristicin, lim- onene, eugenol, and alpha thujene. It plays an important role in the treatment of patients with Alzheimer's disease by preventing neurological damage to the brain [4]. Turmeric (containing curcumin compound) affects the beta-amyloidogenesis of Alzheimer's patients by intensifying the activity of monocytes and macrophages [5]. Thymus vulgaris essential oil contains phenols such as thymol, carvacrol, cinnamon, linaul, and pinene. Inhibition of acetylcholinesterase enzyme by the compounds of this plant can prevent the reduction of acetylcholine in Alzheimer's disease [6]. Hypericum perforatum contains compounds of hypericin, hyperforin, and pseudohypricin and has been effective in the prevention and treatment of Alzheimer's disease [7]. Ethanolic extract of Matricaria chamomilla with restorative effects on the nervous system may be useful in patients with Alzheimer's and behavioral disorders. The enhancement of memory by the extract can be attributed to the antioxidant effects of its active compounds [8]. The efficacy of Salvia officinalis extract in the treatment of mild to moderate Alzheimer's disease has been determined [9]. The main composition of garlic is allicin. Garlic intake may inhibit $A \beta$ accumulation in the human brain and thereby protect the brain and produce an anti-Alzheimer's effect [10]. Recent findings have shown that Ziziphus jujube disrupts memory, a common symptom of various neurological diseases. However, its effects on $\beta$-amyloid toxicity $(A \beta)$ remain clear [11].

Copyright (C) 2020 The Author(s). This is an open-access article distributed under the terms of the Creative Commons Attribution License (http://creativecommons.org/licenses/by/4.0), which permits unrestricted use, distribution, and reproduction in any medium, provided the original work is properly cited. 
Rosemary is a plant that contains compounds 1 and 8-cineol, alpha-pinene and camphene. Neuroprotective effect of rosemary has been implicated in Alzheimer's disease by mechanisms including the prevention of brain inflammation and $\beta$-amyloid toxicity $(\mathrm{A} \beta)$ formation [12]. Cyperus rotundus contains cineole and isoleucine compounds and with anti-acetylcholinesterase effect improves memory and learning in this disease [13]. Medicinal herbs can be used in the treatment of Alzheimer's by their various mechanisms mentioned above and they can be produced in the future as effective natural anti-Alzheimer's drugs.

\section{Authors' contribution}

All authors contributed equally to the manuscript.

\section{Conflicts of interest}

The authors declared no competing interests.

\section{Ethical considerations}

Ethical issues (including plagiarism, data fabrica $\neg$ tion, double publication and etc.) have been completely ob $\neg$ served by author.

\section{Funding/Support}

None.

\section{References}

1. Agronin ME. Practical Guide in Psychiatry. 1st ed. Philadelphia: Lippincott Co; 2004: 72-280.

2. American Alzheimer Association [homepage on the internet]. California: The American Alzheimer Association, Inc;C 1999-2002 [updated2003May22; cited2004 Apr20]. Available from: http://www.alzheimer.Org.uk/statistic. htm.

3. Prince MJ. World alzheimer report 2015: the global impact of dementia: an analysis of prevalence, incidence, cost and trends. London: Alzheimer's Dis Inter. 2015.

4. Douglas S. A. Chaves, Flávia S. Frattani, Mariane Assafim, Ana Paula de Almeida, Russolina B. Zingali, Sônia S. Costa. Phenolic Chemical Composition of Petroselinum Crispum Extract and Its Effect on Haemostasis. Natural Product Communications. 2011, https://doi. org/10.1177/1934578X1100600709

5. Yang F, Lim GP, Begum AM, Ubeda OJ, Simmons MR, Ambegaokar SS, et al. Curcumin inhibits formation of Beta amyloid oligomers, binds plaques and reduce amyloid in vivo. J Biol Chem. 2005; 280(7): 5892-5901.

6. Azizeh Asadzadeh and Fatemeh Heidarian Naeini, 2, The Effect of Thyme in the Suppression of Acetylcholinesterase for the Treatment of Alzheimer's Disease, 19th Annual Research Congress of Medical Students, Hamadan, Student Research Committee of Hamadan University of Medical Sciences, https: // www .civilica.com / Paper-AMSMED19AMSMED19_178.html

7. Zheng Cao, Fan Wang, Chunyu Xiu, Jian Zhang, Yan feiL. Hypericum perforatum extract attenuates behavioral, biochemical, and neurochemical abnormalities in Aluminum chloride-induced Alzheimer's disease rats. Biomed Pharmacoth. 2017; 91: 931-937.

8. Zahra Alibabaei, Zahra Rabiei, Samira Rahnama, Shiva Mokhtari, Mahmoud Rafieian-kopaei. Matricaria Chamomilla extract demonstrates antioxidant properties against elevated rat brain oxidative status induced by amnestic dose of scopolamine. Biomed Aging Pathol. 2014; 4(4): 355-360.
9. Akhondzadeh S, Noroozian M, M. Mohammadi, S. Ohadinia, A. H. Jamshidi, M. Khani. Salvia officinalis extract in the treatment of patients with mild to moderate Alzheimer's disease: a double blind, randomized and placebo-controlled trial. J Clin Phar Therap. https://doi.org/10.1046/j.13652710.2003.00463.x

10. Veer Bala Gupta, S. S. Indi, K. S. J. Rao. Garlic extract exhibits antiamyloidogenic activity on amyloid-beta fibrillogenesis: relevance to Alzheimer's disease. Phytothe Res. 2008; https://doi.org/10.1002/ptr.2574

11. Kwon HY, Jung IH, Yi JH, Kim JH, Park JH, Lee SH, Jung JW, Lee YC, Ryu JH, Kim DH. The Seed of Zizyphus jujuba var. spinosa Attenuates Alzheimer's Disease-Associated Hippocampal Synaptic Deficits through BDNF/TrkB Signaling. Biolog Pharmaceutical Bulletin. 2017; 40(12): 2096-2104.

12. Solomon Habtemariam. The Therapeutic Potential of Rosemary (Rosmarinus officinalis) Diterpenes for Alzheimer's Disease. Evidence-Based Complementary and Alternative Medicine 2016; https://doi.org/10.1155/2016/2680409

13. Rabiei Z, Hojjati M, Rafieian-Kopaei M, Alibabaei Z. Effects of Cyperus rotundus tuber ethanolic extract of learning and memory in animal model of Alzheimer. Biomed Aging Pathol. 2013. 3(4): 185-91. 